\title{
The Powerful Potential of Qualitative Research for Community Psychology
}

\author{
Victoria L. Banyard ${ }^{1}$ \\ University of New Hampshire
}

Kenneth E. Miller

Bosnian Mental Health Program, Chicago, Illinois

This special issue of the American Journal of Community Psychology, focused on qualitative research, is the result of several converging factors. Most immediately, the idea for the special issue was born in the wake of a symposium on "Qualitative Research in Community Psychology" held during the 1995 Biennial Meeting of the Society for Community Research and Action, in Chicago. Despite an early-morning time slot on the final day of the conference, the response to the symposium was tremendous. The room was filled to overflow, and the enthusiasm of those in attendance was evident in the lively discussion that followed the formal presentations. Several themes emerged during the symposium, including (a) an interest in elaborating the nature of qualitative research (i.e., a set of research techniques vs. a paradigmatically distinct way of thinking about, doing, and making use of research), (b) a general sense of agreement that qualitative research methodologies remain greatly underutilized within the field of community psychology, and (c) a shared experience of marginalization among psychologists and graduate students in community psychology who have chosen to employ qualitative rather than, or in addition to, quantitative research strategies in their research. Unfortunately, the discussion of these issues was cut short by the constraints of the time allotted for the ${ }^{1}$ All correspondence should be sent to Victoria L. Banyard, Department of Psychology, University
of New Hampshire, Conant Hall, Durham, New Hampshire 03824; E-mail:vlb@christa.unh.edu. 
symposium. It was clear, however, that an important dialog had begun, and that it would be a worthwhile endeavor to explore ways of continuing that dialog through the various venues of the SCRA. This special issue of AJCP represents one expression of that continued discussion.

For about 30 years, we have relied almost exclusively on traditional quantitative research methodologies to help us understand the problems, strengths, and concerns of the individuals and communities who are the focus of our work. Despite talk of a paradigm shift away from logical positivism (Trickett, 1984), with its reification of quantifiable data, its utilization of reductionistic research methods, and its lesser attention to contextual factors that shape people's experience, there has been surprisingly little effort to explore alternative methodologies that might help researchers transcend the limitations of the traditional positivist approach.

An informal review of research articles published in the American Journal of Community Psychology and the Journal of Community Psychology during the past three decades reveals some interesting patterns. We reviewed over 1,200 studies, noting the type of research methods employed as well as the focus of the research. First, it is clear from the work published in these two journals that community psychologists have done an excellent job of focusing their energies on precisely the types of issues and problems identified as central to the emerging field of Community Psychology in the wake of the Swampscott Conference of 1965 (Anderson et al. 1966). The field was born out of a commitment to addressing the needs and problems of marginalized communities, an interest in preventing rather than treating mental health problems, and a desire to work with disempowered communities to help them gain greater control over the resources and institutions that affect their lives (Levine \& Perkins, 1997). It was readily apparent in our review that community psychologists have stayed true to the progressive identity of the field with regard to the types of communities and issues that are the focus of our research and interventions. Numerous studies have addressed the experience of socially, politically, and economically marginalized groups, including, for example, low-income inner-city communities (Johnson, 1988; Kelly, 1992; Reyes, Gillock, \& Kobus, 1994), people with disabilities (Balcazar \& Keys, 1994), battered women (Sullivan, Campbell, Angelique, Eby, \& Davison, 1994), immigrant and refugee communities (Miller, 1996; Zembrana, Silva-Palacios, \& Powell, 1992), and people who are homeless (Banyard, 1995; Bybee, Mowbray, \& Cohen, 1994). Several studies have examined the "sense of community" (Davidson \& Cotter, 1991; Newbrough \& Chavis, 1986; Plas \& Lewis, 1996), a concept central to the field, and research on empowerment continues to enjoy strong support (Maton \& Salem, 1995; Perkins \& Zimmerman, 1995; Rappaport, 1995; Speer \& Hughey, 1995). Finally, prevention, a somewhat novel idea in the 
early days of the field, has taken on a life of its own, with research and interventions addressing an impressively broad range of topics (e.g., school failure, substance abuse, teen pregnancy, community violence, delinquency).

However, the identity of the field derives not only from the focus of our research but from the particular methodologies we employ and, more fundamentally, from the paradigmatic framework that determines our choice of methodologies. In our review, we found that the field of community psychology has achieved what Trickett (1984) has called a "partial paradigm shift." As community psychologists we have identified a unique range of foci for our research, and have sought to understand the issues we study from a novel perspective, namely, an ecological perspective that views all behavior in relation to the particular geographic, sociocultural, and historical settings in which it occurs. However, we have remained quite traditional in terms of the methodologies we utilize to study the phenomena that interest us. It might be said that we are studying new things in old ways, and have yet to seriously consider whether the addition of nonquantitative methods might provide new and valuable ways of seeing the problems and issues at hand, and might perhaps lead to more effective solutions as well.

We ought, perhaps, to begin by asking what is qualitative research? In fact, the answer is more complicated, and indeed more controversial, than one might initially suppose. On the one hand, some discussions of qualitative research adopt a strictly methodological view, and define it as a set of specific research tools including such things as case studies, focus groups, life histories, in-depth interviews, observations, and analysis of a variety of texts (Denzin \& Lincoln, 1994). However, qualitative research has also been considered from a more explicitly paradigmatic perspective. From this point of view, the specific research methods of qualitative inquiry reflect an underlying philosophy of science, one which eschews the traditional positivist belief in an objective reality that can only be understood through detached scientific inquiry. According to this view, qualitative methods are consistent with, and reflective of, a social constructivist position, in which reality is best understood by studying the ways in which people perceive, experience, and make sense of, the events in their lives. From this point of view, scientific objectivity is regarded as an impossible stance since our values and biases permeate all aspects of the research process; interpersonal detachment is seen as an obstacle to the sharing of personal beliefs; data are considered to be embedded inseparably from the specific contexts in which they are gathered; and the research process is ideally based on collaboration and mutual learning. Our own position entails a bit of fence straddling. On the one hand, we agree with the social constructivist critique of con- 
ventional social science research methods. We firmly believe that qualitative methods can help researchers adopt a more collaborative approach to the process of scientific inquiry, an approach that emphasizes the central role of subjective perception and the construction of personal meanings as determinants of how people experience reality. On the other hand, however, we also believe that qualitative methods can in fact be used simply as a set of research tools, without the adoption of a particular postpositivist paradigm. Used in this way, qualitative strategies can provide rich sources of data that complement or lay the groundwork for contextually grounded qualitative inquiry. We share a concern that too often the polemic surrounding the qualitative-quantitative debate may discourage researchers grounded in quantitative methodologies from experimenting with qualitative approaches.

In this special issue, we have brought together a varied group of community researchers engaged in either partly or wholly qualitative research endeavors. With this issue we sought to present a range of views regarding the ways in which community psychologists might think about, and make use of, qualitative research methods in their work. We hope this diverse presentation will speak, on the one hand, to our colleagues who are already convinced of the value of qualitative methods and wish to see greater discussion and publication of qualitative research in the field. At the same time, we also hope to reach our more quantitatively oriented peers who have yet to be convinced of either the utility or validity of qualitative research methods. To this end, we have invited authors to both present their data and to reflect on the ways in which the incorporation of qualitative strategies has enhanced the quality of their research as well as how it has presented them with unique challenges and limitations.

\section{A CASE FOR GREATER UTILIZATION OF QUALITATIVE RESEARCH METHODS}

A primary motive for putting together this special issue is to advocate for a greater use of qualitative or combined qualitative-quantitative research methodologies by community psychologists. The rationale for this position derives from three premises: (1) qualitative research methods are consistent with the core values of the field of Community Psychology; (2) qualitative methods can lay the groundwork for the development of culturally anchored quantitative methods and measures; and (3) qualitative methods are a powerful set of tools for understanding the "why" of human behavior - the subjective meanings people make of their experiences and 
that give rise to specific behaviors. In the remainder of this introduction we elaborate on these three assertions.

\section{Premise 1: Qualitative Research Methods can Support the Core Values of the Field of Community Psychology}

From the proceedings of the Swampscott Conference to current issues of the American Joumal of Community Psychology and a range of textbooks in the field, there have been numerous discussions of the core values of community psychology (Duffy \& Wong, 1996; Levine \& Perkins, 1987; Sarason, 1974). Although the specific wordings differ there are several consistent themes, including a respect for and emphasis on diversity; the use of an ecological framework which posits that individual and community experience can only be understood contextually, taking into account the present and historical interactions between people and the settings in which they live; and a focus on empowerment, including the development of research processes that are themselves empowering to community members. It is our contention that qualitative research, with its emphasis on capturing the diversity of respondents' experiences, its attention to the context of researched phenomena, and its capacity to document the voices of historically marginalized communities, can greatly facilitate the realization of these core values in our work with communities.

\section{Diversity}

A central value in the field of community psychology is diversity (Trickett, Watts, \& Birman, 1993). An article by Trickett et al. (1993) traced the evolution of community psychology's views on diversity. According to their definition, diversity has to do with an appreciation of the importance of studying the variety of contexts in which people live their lives. Social identity characteristics, such as gender, race, sexual orientation, class, or religion, shape the lived experiences and stories told by various communities and thus are important areas of study for community psychologists. Furthermore, an appreciation for diversity challenges us to look more closely at the origins of so called "general" psychological theories. Trickett et al. stated:

Each reflects a similar concern about the implicit assumptions of theories developed by dominant-culture psychologists . . . . From this perspective, each group has a distinctive worldview which underlies the development of psychology for and by members of that group. This emphasis on cultural pluralism as part of the substance of psychology represents an emphasis on cultural distinctiveness rather than on the 
sociopolitical status shared by these groups in their efforts to gain access to the field. (pp. 267-268).

Trickett $e$ t al. (1993) also asserted that although community psychology has professed to value such diversity, the field has a long way to go in truly addressing issues of diversity in research and practice. What this discussion suggests is that there are several components to understanding diversity. One entails appreciating and trying to understand the multiple perspectives and viewpoints that members of various groups may have-more fully documenting the diverse range of human experiences. A second asserts that we must raise questions about the universality of our so-called "basic" theories in psychology given that they have been created by persons with particular backgrounds and world views. As Harding (1991) has stated, the views of various phenomena that are obtained by looking through the eyes of different groups of people, may lead to the formulation of diverse theories and hypotheses about how such phenomena operate.

As several of the authors in this special issue illustrate, qualitative research methods are ideally suited to putting a valuation of diversity into practice. The link between qualitative research and diversity can be seen when considering qualitative research as purely a set of tools or methods, and also when examining it as reflective of an alternative research paradigm. As a set of tools, methods such as in-depth interviews, participant observation, and focus groups provide extensive, thick description of a phenomenon (Geertz, 1973). This rich description allows us to capture both this diversity and the specificity of human experience. We can more clearly see and begin to articulate individual differences both within and between groups. This is a first step toward capturing and appreciating human diversity.

For example, Banyard (1995) conducted research on the coping strategies of homeless mothers. She was interested not only in capturing the general types of coping employed by the women but also in examining what these strategies were specifically. Although the literature on stress and coping may speak generally about concepts such as "stress in the parenting role" or "use of active-behavioral coping strategies," those interested in working with homeless families must understand the specificity and variety in their particular experiences with such phenomena. Stress as a parent may mean juggling a work schedule with day care and soccer practice for a middle-class professional mother. For homeless women, however, it had much more to do with finding ways to feed hungry children when one's food stamps were not sent or finding ways to answer a child who asks for a piece of candy in the face of having to change schools, live in a shelter, and eat food that is not of the family's choosing. It also means making decisions about whether to buy a child shoes that fit or save money for a 
housing deposit. Furthermore, investigating the phenomenon at this level of specificity enabled the researcher to appreciate differences within the group of homeless mothers in terms of their approaches to life in the shelter (Banyard, 1995). Generating this level of detail and description contributes to our ability as community psychologists to understand and appreciate the diverse experiences of those we work with. It is these specific details which also help us to design the specific aspects of intervention programs that are grounded in participants' lived experiences (Banyard, 1995; Banyard \& Graham-Bermann, 1995).

The thick description of qualitative methods help us to capture the details of multiple voices and perspectives. Indeed, much writing about qualitative research highlights its concern with the emic or insider views of a phenomenon. As Denzin and Lincoln (1994) stated, "qualitative investigators think they can get closer to the actor's perspective through detailed interviewing and observation. They argue that quantitative researchers seldom are able to capture the subject's perspective because they have to rely on more remote, inferential empirical materials" (p. 5). This is important in that a valuing of diversity requires that we work to capture and articulate views of others who may be different from ourselves. Qualitative research does not begin with questionnaires developed from the point of view of the researcher or derived from general theories which may have little relation to the lived experience of the group of interest. Qualitative researchers recognize that there may be a variety of aspects of a phenomenon that are missed if we restrict people to forced-choice answers. Instead, qualitative methods such as in-depth interviews, case studies, or focus groups promote the researcher's ability to capture the perspective of the research participant.

The ability to capture and understand the points of view of different research participants adds new and critical voices to our understanding of phenomena, which in turn give us new information that can be used to develop new or revised theories and constructs as Trickett et al (1993) and others have called for. For example, Way (1995), in her work on the relationships of adolescent African American girls, describes her interest in understanding how African American girls viewed themselves and their relationships. Yet she found that most of the literature on adolescents' views of self and relationships focused on White adolescents. Studies of African American girls mainly utilized a deficits model to focus on risk factors for problematic behavior such as pregnancy or delinquency. Way was interested in developing more of a strengths perspective. She qualitatively analyzed the narratives of 12 African American girls over the course of 3 years. The qualitative interviews revealed some unique and important sources of strength for these urban adolescents and pointed the way to a critical re- 
thinking of views of adolescent girls. Of particular note were their descriptions of their ability to be outspoken about both positive and negative feelings in relationships. This ability to "speak one's mind" (Way, 1995, p.123) provides a different picture of urban African American adolescent girls, who are most often seen in terms of issues such as teen pregnancy or gang violence. It also adds a different and important voice to discussions of adolescent relationships, as studies of predominantly White samples have found a high degree of silencing, or reluctance to openly express views and opinions, among girls. The use of qualitative methods in this study not only broadens our understanding of adolescent girls' relationships but highlights the need to develop more complex theories of female adolescent relationships and news ways of working with adolescent girls that take such new findings into account.

As stated earlier, qualitative research can also be seen as reflecting an alternative scientific paradigm. From this perspective, it reflects a philosophy of science that does not emphasize the importance of scientific objectivity and interpersonal detachment in the research process. Instead, reality is seen as being filtered through local, historical lenses. From this view, our best chance of understanding the world is by appreciating these multiple, local contexts and stories and obtaining rich detail about them. For example, to understand homelessness or teen pregnancy, we need to consider the role of local and historical variables that may contribute to these phenomena and may make the experience of these issues very different for each individual. An important corollary to this is the understanding that researchers also view the world through local and historical lenses and thus need to consider their own values and biases as they influence the research process. We are encouraged to examine the diversity that exists within the research relationship, and to consider how differences in life experience, racial and ethnic background, and other variables may affect the nature of the data that is collected and the questions that are asked. Too often the researcher is treated as an invisible other, a neutral instrument whose personal characteristics do not significantly shape the responses of research participants. Recently, however, a growing number of researchers have questioned the validity of this view, suggesting instead that what research participants share in the course of data collection is fundamentally affected by their perception of the whole research process, including the person of the researcher (Banyard, 1994; Harding, 1991; Miller, 1994; Scheper-Hughes, 1991).

Harding (1991), for example, called for the insertion of the researcher into the text of our research. She stated: "The purportedly universal perspective is in fact, local, historical, and subjective ..." (p. 273). As scientists, this position encourages us to take responsibility for our own social situ- 
ation and the fact that such a position gives us only one view of the world. Angrosino (1989) provided an interesting example of this. He discussed a comparison he was able to make between a life history that he collected of a woman on a small Caribbean island and a life history of the same woman collected by a local historian on the island. While the basic facts of her life story were the same, there were many important differences that Angrosino attributed to the differences in researcher-participant relationship because of the characteristics of the researcher. He stated:

The resulting life history is thus a document of a particular relationship - it reflects both what the researcher has elicited... and what the subject has chosen to tell that researcher .... the interviewer is as much an author of the resulting text as is the person whose life is the topic of discussion, because he or she provides the socially recognizable cues to which the life history subject responds in telling about his or her life. (p. 315-316)

Qualitative research, in its focus on thick description of specific contexts may help us to pay closer attention to the unique relationship of researcher and participant and also provide space for a careful consideration of the researcher's individual standpoint and its impact on the research.

These examples illustrate that using qualitative research either as a set of methods or as reflective of a different philosophy of science promotes an appreciation, respect for and an ability to document diverse perspectives, a fundamental value of community psychology. Qualitative research methods can assist us in capturing the multiple standpoints of community members which in turn will assist us in creating theories and interventions that are more inclusive and representative.

\section{Context}

It is an axiom of the ecological model that human behavior can only be understood when viewed in context, that is, when the various ecological determinants of behavior are taken into consideration (Trickett Kelly, \& Vincent, 1985). For example, the widespread participation in gangs among many inner-city youth illustrates how such determinants may be historical (e.g., the loss of jobs in communities leads to high rates of unemployment and underemployment, local businesses close or move elsewhere, and the quality of schools deteriorates with a resultant increase in school failure); physical (e.g., a lack of safe and adequate housing, a paucity of public recreation areas); social (e.g., racism; a sense of isolation among neighborhood residents instead of a strong sense of community or social embeddedness); or they may be political and/or socioeconomic (e.g., cuts in public spending that result in day care shortages, increased homelessness, loss of job training) (Wilson, 1996). The neglect of these multiple layers of behavioral de- 
terminants was at the heart of the critique of mainstream psychology articulated by community psychologists writing during the field's formative years (Anderson et al., 1966). Several authors (Trickett et al., 1985) have noted with concern the failure of academic researchers to adequately consider contextual factors that shape the behavior of people in communities, and have observed that this neglect of context has frequently given rise to an overemphasis on individual determinants and a dangerous, if perhaps unintended, practice of concluding that failure and hardship reflect the functioning-or more precisely the malfunctioning-of precisely these intraindividual factors.

Qualitative research methods-focus groups, setting observations, semistructured and unstructured interviews, participation in the daily life of community residents, and document analysis-are ideally suited to helping community researchers counter this traditional neglect of context. Such methods allow the development of a "thick description" (Geertz, 1973), a detailed examination of specific behaviors and the settings in which they occur. Denzin and Lincoln (1994) stated, "Qualitative researchers are more likely than quantitative researchers to confront the constraints of the everyday social world. They see this world in action and embed their findings in it (p. 5). Specific types of qualitative research further illustrate this point. Boyle (1994) described a central assumption of ethnography, a prevalent form of qualitative research: "A central tenet of ethnography is that people's behavior can be understood only in context; that is, in the process of analysis and abstraction, the ethnographer cannot separate elements of human behavior from their relevant contexts of meaning and purpose" (p.162). During the fieldwork process, researchers interact with participants in their natural settings rather than in the laboratory. This permits observation of the context in which particular phenomenan occur.

An example of this is provided by Nations and Rebhun (1988), who took issue with the findings of Scheper-Hughes (1992) that poor women in northeastern Brazil coped with the poverty-related deaths of their children by selectively attaching to those most likely to survive and consequently did not grieve deeply the loss of their more sickly offspring. This conclusion was based at least partly on Scheper-Hughes' observation that the supposedly bereaved mothers did not appear to cry or to experience outwards signs of grief in the wake of their children's deaths. Using indepth interviews with a similar sample of Brazilian mothers, Nations and Rebhun discovered a popular folk belief which held that a mother's tears would weigh down the wings of her child's angel-spirit as it ascended to heaven. Woman after woman revealed to the researchers the private anguish they experienced following the loss of any of their children, and the terrible, private struggle they engaged in to avoid any outward expression 
of their grief. It was only through phenomenological interviews that the women's apparent lack of maternal grief was made comprehensible to the researchers, as the cultural determinants of their behavior were revealed. Undeniably, the incorporation of ethnographic methods can be time-consuming; however, the risks entailed by failing to understand important ecological determinants of behavior can lead to inaccurate and potentially destructive conclusions.

\section{Empowerment}

In addition to the values discussed above, community psychology also very much embraces the notion of empowerment. Rappaport (1990) outlined a number of dimensions of empowerment research including giving voice to the experiences and the strengths of disenfranchised groups and facilitating collaboration with research participants. Closely linked to this is community psychology's value of social change and action. Here too, qualitative research is instrumental (Rappaport, 1990). Qualitative methods by their nature document the voices of participants. Mishler (1986) stated:

The effort to empower respondents and the study of their responses as narratives are closely linked. They are connected through the assumption .... that one of the significant ways through which individuals make sense of and give meaning to their experiences is to organize them in a narrative form . . . various attempts to restructure the interviewee-interviewer relationship so as to empower respondents are designed to encourage them to find and speak in their own "voices." (p. 118)

Research methods such as open-ended interviews and focus groups, which have historically been part of a more qualitative research tradition, permit research to be a tool not only for gathering information but for individual and group empowerment as well as action and social change. For example, qualitative techniques can provide a vehicle for participants to tell their story in their own words. This can be empowering on an individual level. In a recent study of homeless mothers (Banyard, 1995), the women interviewed often seemed to feel that the open-ended nature of the interviews allowed them more room to craft their own interpretations and answers rather than the forced-choice questionnaires they had also completed. Some commented that they felt that they had really been "heard" and that the open-ended discussions had helped them to step back from their experiences and see them a bit differently. There were times, too, when interactions with interviewers would create different understandings of their experiences, such as when they were asked about strengths that they had-not a question they were often asked. Such findings suggest possibilities for the type of transformative and empowering 
learning that Friere (cited in Yeich \& Levine, 1992) stated comes from interactions with others.

Qualitative methods can be empowering at the community level as well. Both Scheper-Hughes (1991) and Miller (1994) have described the ethnographer who works with marginalized communities as a kind of historian who documents the communal stories of oppression and struggle that are denied, distorted, or covered up by those in power. In the preface to his psychological study of Guatemalan survivors of government orchestrated genocide, Miller (1994) noted:

\begin{abstract}
This research is also an act of .. history taking, as it were, in a community whose history of oppression has continually been denied and covered up by those in power in Guatemala and elsewhere (e.g. the United States)....the Guatemalan government and military have blamed the refugees, whom they label "communist subversives" and "terrorists", for their experience of oppression at the same time that the reality of that experience has been questioned and denied. In writing and speaking about the experiences of the refugees, and in sharing with others the stories that were shared with me during the eight months I worked in the camps, my hope is to set the record just a bit straighter. (p. xiv)
\end{abstract}

The power of qualitative methods to document the truth of people's experiences, in their own words, becomes a source of empowerment by (a) affirming the reality of a community's historical experience and documenting that experience in written form; and (b) facilitating the dissemination of these communal stories through publication and oral transmission to a wider audience, a process which can in turn draw greater attention and resources to the needs and concerns of the community.

Feminist researchers have also noted the power of documenting women's life histories. Both Mies' (1983) work with battered women and Benmayor's (1991) literacy project with Puerto Rican women discuss the individual-level empowerment that comes from developing one's own life history and from being able to look at one's experiences from a distance. Their work also suggests a way to take this process a step further by having participants share their own stories with one another. This may take place through group interviews, focus groups, having participants read written life histories to a group, or by having participants conduct interviews with one another. Both Mies (1983) and Benmayor (1991) noted that when participants shared their narratives with other participants, it led to the development of collective support and broader group consciousness. Magill (1993) conducted focus groups with a sample of low-income clients who were involved in a pilot energy program for low-income individuals. Focus groups were used as part of the program evaluation. Magill stated, "The case example demonstrated that focus groups with low income respondents can be a mechanism for clients to participate in social change. Support from other group members can empower low income clients to express critical views of 
authorities and of established programs or institutions" (p. 112). Sharing the history of one's experiences can raise group consciousness about systems of oppression, generate a sense of shared circumstances, reduce self blame, and help individuals understand the sociopolitical context of their circumstances. All of these are key elements in the process of empowerment (Allen \& Barr, 1990; Gutierrez, 1990; Rappaport, 1984, 1987). Qualitative strategies such as focus groups, interviews, and life histories, are all methods that can function both as research tools and as instruments to facilitate individual and group empowerment. Indeed, the power of using narratives in research on empowerment has been recently highlighted by Rappaport (1995), who stated that narratives can help disenfranchised communities to develop new and important stories about their communities that can support more empowering and strengthening personal and community views of self. Furthermore, "in addition to the content discovered, the metacommunications that follow from listening to and giving respect to the stories of people's lives tends in itself to be an experience that changes the role relationship from researcher and subject to coparticipants" (p. 801).

\section{Premise 2: Qualitative methods can lay the groundwork for the development of culturally anchored quantitative methods and measures}

Beyond the ways in which qualitative research is consistent with the values of community psychology, these methods can do much to improve our quantitative research. Qualitative methods can provide researchers with conceptual roadmaps in previously uncharted territory. As community psychologists, we are frequently engaged in research and intervention projects with socially marginalized communities that have historically been excluded from mainstream psychological research, and for whom culturally informed, appropriately standardized research instruments are unavailable. By utilizing qualitative methods such as focus groups, individual interviews, and ethnographic observation during the initial stages of research in such communities, researchers can identify contextually salient variables, while avoiding the imposition of inappropriate norms and constructs derived from research with other populations. In the language of cultural anthropology, qualitative methods can facilitate an emic understanding of specific cultural settings, which in turn significantly enhances the development of culturally anchored measures and methods of intervention (Maton, 1993).

There are several examples of community researchers who have used qualitative methods to inform the development of quantitative instrumentation. Maton's (1993) work utilized ethnographic methods (e.g., participant observation, individual interviews, and document analysis) to lay the ground- 
work for subsequent questionnaire-based research on behavioral change on the direction of shared group ideals among members of the New Covenant Fellowship, a nontraditional religious community. To build a research project that was based on the lived experiences of this group of individuals who were not included in more "general" theories of psychology, he began with qualitative methods to understand more about such things as the support systems used in various communities. He stated, "the ethnographic tradition in anthropology and sociology has as its primary goal the understanding of the world views, values, language, and practices of members of a culture markedly different from that of the researcher" (Maton, 1993, p.748). The use of such methods helps us to develop quantitative measures that more accurately and completely capture the phenomenon of interest.

Another example can be seen in work by Hughs and DuMont (1993) on parenting in African American families. They were interested in the ways in which parents' jobs might influence socialization of children, particularly the impact of stressors that were work-related on racial socialization of children. Qualitative focus groups were used to generate data grounded in participants' own experiences, data that were then used to design quantitative measures that were culturally valid. For example, the focus group information helped researchers revise the wording of items to be more linguistically consistent with the community they were assessing. It also helped researchers develop new items to assess experiences that participants indicated as being important but that were not included on quantitative instruments currently available in the field. A recent study by Mitchell and Beals (1997) used ethnography to inform the quantitative study of positive and negative behaviors among American Indian adolescents. Ethnographic information helped researchers select key measures that would be valid for this population as well as helped modify such things as the language used in collecting data. Ethnographic information was also used to check the interpretations and conclusions made from the quantitative data. In the present issue, the use of qualitative methods to lay the groundwork for quantitative instrumentation is illustrated by the work of Dumka and Gonzales, Wood, and Formoso who used a combination of individual interviews and focus groups to study parenting concerns and parent-child conflict in low-income Latino, African American, and Anglo families.

\section{Premise 3: Qualitative methods are a powerful set of tools for understanding the "why" of human behavior}

Borrowing the famous phrase of radio host Paul Harvey, we suggest that qualitative research can also help us tell "the rest of the story" re- 
garding the issues and problems that concern us in our research and interventions. There is a growing sense that perhaps quantitative measures, no matter how culturally sensitive, simply cannot tell the whole story of the issues that affect the individuals and communities with which we work. It may be, for example, that only in their own voices, in narratives unconstrained by the limitations of forced-choice answer categories, can children help us make sense of why they cope with major life stressors in the ways they do. For example, the child who becomes anxious and self-critical in the wake of parental divorce may privately interpret the dissolution of her parents' marriage as the result of her own misbehavior; her consequent attempts to "be good" in the hopes of parental reconciliation can only be understood when the subjective meaning she has made of the divorce is revealed. A unique strength of qualitative methods is precisely their capacity to permit an exploration of respondents' subjective interpretations of life events - the personal meanings they create and the feelings and cognitions that underlie and result from the meaning-making process. Such methods offer research participants the opportunity to share their experiences using whatever words and metaphors they choose, rather than having to reduce their experience so that it fits into a range of predefined answer choices.

This point underscores the essential complementarity of qualitative and quantitative methods. Despite a polarized and often contentious debate between proponents of the two approaches, it is our view that each set of methods is uniquely suited to addressing certain kinds of questions, certain aspects of whatever phenomena we choose to study. For example, whereas quantitative methods permit the identification of specific patterns of behavior, qualitative methods reveal the subjective meanings that underlie and give rise to these behaviors. Rank (1992) has nicely illustrated this point in his study of childbearing among women in Wisconsin. Interested in the popular stereotype that women receiving public aid give birth to more children than do women not on welfare, Rank analyzed birth rates for women in Wisconsin from 1980 to 1983 . His data revealed that in fact, women on public aid had a significantly lower birth rate during this period than did their financially better off peers. To understand the reasons behind these results, Rank then used qualitative interviews with women in the public aid group to understand why they chose to have fewer children than women with better financial resources. The women he interviewed gave various reasons, such as the financial burden imposed by additional children and a desire to be able to provide adequately for any children they might have in the future.

There are other ways in which qualitative methods can help us make sense of findings derived from quantitative assessments. In his research with 
Guatemalan refugee children, Miller (1996) used a behavior checklist to assess patterns of distress among children in two refugee camps. Surprised by the low prevalence of psychological disturbance among children in these communities with histories of extreme political violence and forced exile, Miller used ethnographic methods to understand the role of individual, familial, and community factors that contributed to the children's resilience. Participant observation revealed a "recreation of normality" within the camps, in which traditional patterns of work, play, socializing, and religious practice were maintained to the extent possible in the refugee camps. Despite the chaos and violence of the past, the children's world was relatively stable and predictable, and retained many of the socially supportive relations that characterized life in their communities of origin. Mornings were spent in school, afternoons were spent doing homework and chores and playing with friends, and in the evening families ate dinner together and socialized until bedtime. Family ties were maintained among relatives who had gone into exile together, so that many children had regular access to extended family members who played supportive roles in their upbringing. In short, qualitative methods revealed a wide variety of factors in the children's environment that facilitated healthy adaptation among the majority of the children, despite the violence of the past and the ongoing sense of dislocation experienced by the refugees.

\section{THE SPECIAL ISSUE}

In this special issue, we, along with the collection of researchers whose work appears in this issue, suggest that community psychology's nearly exclusive reliance on quantitative methods has limited our capacity to fully understand the complex challenges and problems that confront the communities with whom we are engaged. The shift to an ecological paradigm, so often cited as a defining feature of the field, implies not merely a shift in what we choose to study, but also a reconsideration of how we go about studying things. Quantitative methods are ideal for examining patterns of behavior and change across time, especially with large samples. They permit the development of sophisticated causal models that serve as blueprints for preventive interventions and allow for replicability across settings. On the other hand, quantitative methods seem poorly suited to helping us understand the meanings people make out of significant events in their lives. Numbers may describe experience, but they too often do not give voice to it, and somewhere along the line the human element too often gets lost in the presentation of complex statistical analyses. 
The purpose of this special issue is not to advocate for one approach over another. We share the view that quantitative and qualitative methods reveal different aspects of the phenomena of interest to us, and consequently may function in a complementary fashion. On the other hand, we believe there is merit in the position of those who argue that the decision to use qualitative versus quantitative methods may be more than a simple choice of data-gathering techniques. According to this argument, each set of methods reflects a distinct set of beliefs about the nature and purpose of research, the types of knowledge considered to be valid, and the appropriate relationship of researchers to those who participate in their investigations (Guba \& Lincoln, 1994). Our hope is that this special issue will open an important dialog about the nature and utility of qualitative research within our specific field of community psychology.

The papers included in this special issue highlight a number of issues that have been raised in this introductory piece. The first paper by FosterFishman, Salem, Chibnall, Legler, and Yapchai uses interview and observational data to investigate the process of empowerment in the workplace and how experiences of empowerment shift with different contexts. This work is an excellent illustration of the utility of qualitative methods for helping us understand the context of phenomena as well as for understanding the process or "why" of human behavior. The following paper by Campbell and Ahrens also illustrates the importance of using research methods that enable us to capture the rich details of community problems and solutions. Their paper uses interviews with various participants in an integrated community services coalition for rape survivors. Their study illustrates in great detail, the functions of integrated services within a community and the potential benefits for sexual assault survivors. Both of these papers also indicate how qualitative methods are reflective of the use of a different scientific paradigm for conceptualizing and conducting research.

In the following paper, Kalafat and Illback use qualitative methods such as semi-structured interviews, on-site observations, and archival review as primary steps in their process evaluation of school-based family resource centers. Using as their starting point the difficulty of finding an adequate set of standardized measures to assess centers that are different from one another in numerous ways, the authors opted instead to focus on local, qualitatively based descriptions of a representative sample of centers. The data they collected served as the foundation for the design of quantitative assessment instruments and provided guidelines to inform practice in other developing centers.

Dumka $e t$ al. illustrate the use of qualitative research to develop a culturally grounded quantitative measure of parenting stress among lowincome, ethnically diverse parents of adolescents. They also use information 
from interviews and focus groups to generate information about parenting programs, capturing the view of parents themselves and the content and process factors parents felt would be key to address. Their work illustrates the utility of qualitative methods for laying the groundwork for the development of culturally anchored quantitative measures, and for developing community interventions that incorporate the perspectives of prospective program participants.

Work by Maton and Hraboski use individual and group interviews to understand familial and community factors associated with high academic achievement among African American males. These researchers note the paucity of data regarding academic "success" among African American youths, since much of the research on minority youths has been framed within a deficits perspective that focuses on dysfunction rather than on success and the variables associated with it. Their research illustrates the utility of qualitative methods for identifying and illuminating previously unidentified or poorly understood variables and provides an important first step in the development of new, more inclusive theories of academic achievement.

Finally, the piece by Tandon, Azelton, and Kelly shows us that qualitative methods may be useful tools for self-evaluations in community organizations. In collaboration with a community organization, these researchers used qualitative interviews and case studies to help the organization better understand the motivations and concerns of community activists involved with The Developing Communities Project, a grass roots community organization in Chicago. The authors illustrate a creative approach to the presentation and analysis of qualitative data, and link that approach to the specific needs of the organization and its members.

\section{REFERENCES}

Allen, J., \& Barr, D. (1990). Experiencing the empowerment process: Women and development. Networking bulletin: Empowerment and Family Support, 1, 1-21.

Angrosino, M. (1989). The two lives of Rebecca Livingstone: Symbolic interaction in the generation of the life history. Joumal of Anthropological Research, 45, 315-326.

Anderson, L., Cooper, S., Hassol, L., Klein, D., Rosenblum, G., \& Bennett, C. (1966). Community psychology: $A$ report of the Boston conference on the education of psychologists for community mental health. Boston: Boston University Department of Psychology.

Balcazar, F., \& Keys, C. (1994). Teaching self-help to vocational rehabilitation clients. Directions in Rehabilitation Counseling, 5, 1-11.

Banyard, V. L. (1994). Sunvival on the streets: Coping strategies of mothers who are homeless. (Doctoral dissertation, University of Michigan, 1994). Dissertation Abstracts International, 55(08), 3578B. 
Banyard, V. L. (1995). "Taking another route": Daily survival narratives from mothers who are homeless. American Joumal of Community Psychology, 23, 871-891.

Banyard, V. L., \& Graham-Bermann, S. A. (1995). Building an empowerment policy paradigm: Self-reported strengths of homeless mothers. American Journal of Orthopsychiatry, 65, 479491.

Benmayor, R. (1991). Testimony, action research, and empowerment: Puerto Rican women and popular education. In S. Berger Gluck \& D. Patai (Eds.), Women's words: The feminist practice of oral history (pp. 159-174). New York: Routledge.

Boyle, J. S. (1994). Styles of ethnography. In J. Morse (Ed.), Critical issues in qualitative research (pp.159-185). Thousand Oaks, CA: Sage.

Bybee, D., Mowbray, C., \& Cohen, E. (1994). Short versus long term effectiveness of an outreach program for the homeless mentally ill. American Joumal of Community Psychology, 22, 181-209.

Davidson, W. B., \& Cotter, P. R. (1991). The relationship between sense of community and subjective well-being: A first look. Joumal of Community Psychology, 19, 246-253.

Denzin, N. K., \& Lincoln, Y. S. (1994). Introduction: Entering the field of qualitative research. In N. Denzin \& Y. Lincoln (Eds.), Handbook of qualitative research (pp.1-17). Thousand Oaks, CA: Sage.

Duffy, K. G., \& Wong, F. Y. (1996). Community psychology. Boston: Allyn and Bacon.

Geertz, C. (1973). The interpretation of cultures. New York: Basic Books.

Guba, E., \& Lincoln, Y. S. (1994). Competing paradigms in qualitative research. In N. Denzin \& Y. Lincoln (Eds.), Handbook of qualitative research (pp. 105-117). Thousand Oaks, CA: Sage.

Gutierrez, L. (1990). Working with women of color: An empowerment perspective. Social Work, 35, 149-153.

Harding, S. (1991). Whose science? Whose knowledge? Thinking from women's lives. Ithaca, NY: Cornell University Press.

Hughs, D., \& DuMont, K. (1993). Using focus groups to facilitate culturally anchored research. American Journal of Community Psychology, 21, 775-806.

Johnson, D. (1988). Primary prevention of behavior problems in young children: The Houston parent-child development center. In R. Price, E. Cowen, R. Lorion, \& J. Ramos-McKay (Eds.), 14 ounces of prevention, (pp. 44-52). Washington, D.C.: American Psychological Association.

Kelly, J. (1992). Ecological inquiry and collaborative enterprise: A commentary on the "Chicago experience." In J. G. Kelly (Chair), African-American leaders: Research as a collaborative process. Symposium conducted at the annual meeting of the American Psychological Association.

Levine, M., \& Perkins, D. V. (1987). Principles of community psychology: Perspectives and applications. New York: Oxford University Press.

Magill, R. S. (1993). Focus groups, program evaluation, and the poor. Joumal of Sociology and Social Welfare, 20, 103-114.

Maton, K. I. (1993). A bridge between cultures: Linked ethnographic-empirical methodology for culture anchored research. American Joumal of Community Psychology, 21, 747-773.

Maton, K., \& Salem, D. (1995). Organizational characteristics of empowering community settings. American Joumal of Community Psychology, 23, 631-656.

Mies, M. (1983). Towards a methodology for feminist research. In G. Bowles \& R. Duelli Klein (Eds.), Theories of women's studies (pp. 117-139). London: Routledge \& Kegan Paul.

Miller, K. (1994). Mental health and meaning making among indigenous Guatemalan refugee children in Chiapas, Mexico. Unpublished doctoral dissertation, University of Michigan, Ann Arbor.

Miller, K. (1995). "Interesting yes, but is it valid?" Obstacles to the utilization of qualitative methods in community psychology. Paper presented at the Biennial Meeting of the Society for Community Research and Action, Chicago. 
Miller, K. (1996). The effects of state terrorism and exile on indigenous Guatemalan refugee children: A mental health assessment and an analysis of children's narratives. Child Development, 67, 89-106.

Mishler, E. G. (1986). Research interviewing: Context and narrative. Cambridge, MA: Harvard University Press.

Mitchell, C. M., \& Beals, J. (1997). The structure of problem and positive behavior among American Indian adolescents: Gender and community differences. American Joumal of Community Psychology, 25, 257-288.

Nations, M., \& Rebhun (1988). Angles with wet wings won't fly: Maternal sentiment in Brazil and the image of neglect. Culture, Medicine, and Psychiatry, 12, 141-200.

Newbrough, J., \& Chavis, D. (1986). Psychological sense of community. I: Forward. American Journal of Community Psychology, 14, 3-5.

Perkins, D., \& Zimmerman, M. (1995). Empowerment theory, research, and application. American Journal of Community Psychology, 23, 569-580.

Plas, J., \& Lewis, S. (1996). Environmental factors and sense of community in a planned town. American Joumal of Community Psychology, 24, 109-144.

Rank, M. (1992). The blending of qualitative and quantitative methods in understanding childbearing among welfare recipients. In J. Gilgun, K. Daly, \& G. Handel (Eds.), Qualitative methods in family research. Newbury Park, CA: Sage.

Rappaport, J. (1984). Studies in empowerment: Introduction to the issue. Prevention in Human Services, 3, 1-7.

Rappaport, J. (1987). Terms of empowerment/exemplars of prevention: Toward a theory for community psychology. American Journal of Community Psychology, 15, 121-145.

Rappaport, J. (1990). Research methods and the empowerment social agenda. In P. Tolan, C. Keys, F. Chertok, \& L. Jason (Eds.), Researching Community Psychology: Issues of theory and methods (pp.51-63). Washington, DC: American Psychological Association.

Rappaport, J. (1995). Empowerment meets narrative: Listening to stories and creating settings. American Journal of Community Psychology, 23, 795-807.

Reyes, O., Gillock, K., \& Kobus, K. (1994). A longitudinal study of school adjustment in urban, minority adolescents: Effects of a high school transition program. American Journal of Community Psychology, 22, 341-370.

Speer, P., \& Hughey, J. (1995). Community organizing: An ecological route to empowerment and power. American Journal of Community Psychology, 23, 729-748.

Sarason, S. (1974). The psychological sense of community: Prospects for a community psychology. San Francisco, CA: Jossey Bass.

Scheper-Hughes, N. (1992). Death without weeping: The violence of everyday life in Brazil. Berkeley: University of California Press.

Sullivan, C. Campbell, R., Angelique, H., Eby, K., \& Davidson, II, W. (1994). An advocacy intervention program for women with abusive partners: Six-month follow-up. American Journal of Community Psychology, 22, 101-122.

Trickett, E. (1984). Toward a distinctive community psychology: An ecological metaphor for the conduct of community research and the nature of training. American Joumal of Community Psychology, 12, 261-279.

Trickett, E., Kelly, J., \& Vincent, T. (1985). The spirit of ecological inquiry in community research. In E. Susskind \& D. Klein (Eds.), Community research: Methods, paradigms, and applications (pp. 283-333). New York: Praeger.

Trickett, E. J., Watts, R., \& Birman, D. (1993). Human diversity and community psychology: Still hazy after all these years. Joumal of Community Psychology, 21, 264-279.

Way, N. (1995). "Can't you see the courage, the strength that I have?" Listening to urban adolescent girls speak about their relationships. Psychology of Women Quarterly, 19, 107128.

Wilson, W. J. (1996, August, 18). When work disappears. The New York Times Magazine, pp. 26-31, 40, 48, 52-54.

Yeich, S., \& Levine, R. (1992). Participatory research's contribution to a conceptualization of empowerment. Journal of Applied Social Psychology, 22, 1894-1908. 
Zembrana, R., Silva-Palacios, V., \& Powell, D. (1992). Parenting concerns, family support systems, and life problems in Mexican-origin women: A comparison by nativity. Journal of Community Psychology, 20, 276-288. 